\title{
SULUH
}

JURNAL BIMBINGAN DAN KONSELING

UMP

http://journal.umpalangkaraya.ac.id/index.php/suluh Volume 6 Nomor 1, September 2020 (16-24)

\section{PENGARUH BIMBINGAN KLASIKAL DEGAN MEDIA AUDIO VISUAL UNTUK MENGEMBANGKAN KONFORMITAS POSITIF SISWA KELAS VIII SMP NEGERI 5}

\author{
The Effect Of Classical Counseling Of Visual Audio Media To Develop Positive \\ Conformity Of VIII Grade Students Of Smp Negeri 5 \\ 'Avif Nur Khanifa, ${ }^{2}$ Dini Rakhmawati, ${ }^{3}$ Ismah \\ Universitas PGRI Semarang. Semarang, Jawa Tengah, Indonesia \\ 2Universitas PGRI Semarang. Semarang, Jawa Tengah, Indonesia \\ 3Universitas PGRI Semarang. Semarang, Jawa Tengah,Indonesia
}

ARTIKEL INFO

Diterima :

Juli 2020

Dipublikasi

September 2020 *e-mail :

Apipnur13@gmail.com

\section{ABSTRAK}

Tujuan yang ingin dicapai dalam penelitian ini adalah untuk mengetahui pengaruh bimbingan klasikal dengan media audio visual untuk mengembangkan konformitas positif siswa kelas VIII SMP Negeri 5 Rembang. Jenis penelitian adalah penelitian eksperimen dengan desain penelitian true eksperimen design dengan jenis One Group Pre-test and Post-test design. Peneliti menggunakan sebanyak 32 siswa untuk kelompok eksperimen. Metode pengumpulan data menggunakan skala psikologi, wawancara. Teknik yang digunakan dalam penelitian ini adalah cluster random sampling. Hasil penelitian kelompok eksperimen skor pretest rata-rata 62,I (kategori tinggi) dan kelompok kontrol sebesar 5I,I. Hasil post-test menunjukkan rata-rata kelompok eksperimen sebesar 63,5 (kategori tinggi) dan kelompok kontrol sebesar 48,8.Sehingga terjadi peningkatan rata-rata pada kelompok eksperimen sebesar I,4.Hasil uji hipotesis diperoleh hasil thitung = I5, 17.Dikonsultasikan dengan tabel taraf signifikansi $5 \%(0.05)$ yaitu 2,042. Hal tersebut menunjukkan bahwa thitung $=15,17>t_{\text {tabel }}=2,042$. Disimpulkan bahwa ada pengaruh bimbingan klasikal dengan media audio visual untuk mengembangkan konformitas positif siswa Kelas VIII SMP Negeri 5 Rembang.

Kata kunci: Bimbingan klasikal dengan media audio visual, Konformitas Positif

\section{ABSTRACT}

The research is aimed at finding out whether or not ther is an effect in classical guidance of audio visual media to develop positive conformity student's VIII at SMP Negeri 5 Rembang.The research was true experimental with one group pre-test and post-test Design. Date. The research used 32 student's for experimental group. The research methods date used sychological scale, interview.. The research technique with cluster random sampling. The reasarch result experimental group score pretest 62, I (high category) and control group 5I,I. The result postest experimental group 63,5 (high category) and control group 48,8. An increase experimental group I,4. Based on the result hypothesis of 15, I7 tcount which then consulted with ttable at significance level of 2,042 so tcount> ttable. It was concluded effect inclassical guidance of audio visual to develop positive conformity student's VIII at SMP Negeri 5 Rembang.

Keywords: Classical guideance with audio visual media, positive conformity

Orcid :

(C) Universitas Muhammadiyah Palangkaraya 
Jurnal Bimbingan dan Konseling

\section{PENDAHULUAN}

Masa remaja merupakan periode perubahan, diantaranya perubahan sosial yang menuntut kemampuan individu dalam perubahan tanpa kemampuan mengikuti perubahan yang demikian cepat yang akan mengakibatkan timbulnya masalah-masalah yang bersifat pribadi dan sosial, khususnya dalam bentuk yang sering diistilahkan dengan "mal-adjusted". Dengan kata lain, masalah individu ada yang bersifat pribadi dan ada yang bersifat sosial. Individu mengalami kesulitan dalam membina hubungan dengan individu lain atau lingkungan sosialnya. Masalah ini dapat timbul karena individu kurang mampu atau gagal berhubungan dan berinteraksi dengan lingkungan sosialnya yang kurang sesuai dengan keadaandirinya. Manusia adalah makhluk sosial berhubungan dengan sesama manusia. Bersosialisasi pada dasarnya merupakanproses penyesuaian diri terhadap lingkungan, baik dalam kelompok kecilmaupun dalam kelompok masyarakat luas. Sikap remaja awal yang berkembang lebih menonjol adalah sikap sosial, terlebih lagi yang berkaitan dengan teman sebaya. Setelah mengenal kepentingan dan kebutuhan yang sama, sikap positif remaja awal terhadap teman sebaya berkembang dengan pesat. Sikap setia kawan sangat dirasakan dalam kehidupan kelompok, baik yang dibentuk secara sengaja maupun yang terbentuk dengan sendirinya. Dalam usia remaja awal, simpati dan empati sudah mulai berkembang. Remaja berusaha bersikap sesuai dengan norma-norma kelompoknya. Sikap itu selalu dipertahankan remaja meskipun bisa menimbulkan berbagai konflik antara remaja dengan orang tuanya akibat perbedaan nilai. Seseorang yang telah merasa cocok dengan teman atau kelompoknya, cenderung untuk mengikuti gaya teman atau kelompok tersebut.Sangat sulit bila remaja tidak mengikuti gaya kelompoknya yang dirasanya buruk tetap mempertahankan diri didalam kelompok karena akan diasingkan jika tidak mengikuti gaya hidup kelompoknya. Keinginan yang kuat anak untuk melepaskan diri dengan menjadi apa yang mereka ingin membuat remaja mencari dukungan sosial melalui teman sebaya. (Peer group) menjadi suatu sarana sekaligus tujuan dalam pencarian jati diri mereka. Banyak ditemukan kasus perilaku remaja yang disebabkan pengaruh buruk dari kelompok teman sebaya ini.

Pada dasarnya tidaklah mudah bagi remaja untuk menyatukan diri mereka pada suatu kelompok karena suatu kelompok memiliki tuntutan yang harus dapat dipenuhi oleh setiap remaja yang ingin bergabung. Adapun tujuan dari penelitian yaitu untuk mengetahui pengaruh bimbingan klasikal dengan media audio visual untuk mengembangkan konformitas positif siswa kelas VIII SMP Negeri 5 Rembang.Namun kenyataanya hal ini juga terjadi di SMP Negeri 5 Rembang khususnya siswa kelas VIII dimana terdapat beberapa siswa yang belum dapat membaur dengan baik bersama teman lainnya, terbentuk kelompok-kelompok teretentu, membolos dan merokok, dan sikap kurang menghargai antar teman dan guru. Hal ini dapat dibuktikan dari hasil analisis AKPD (Angket Kebutuhan Peserta Didik) yang disebar pada tanggal 2I Oktober 2017 dimana menunjukkan bahwa Saya belum banyak teman atau sahabat dengan prosentase $2,97 \%$, kata maaf, tolong dan terimakasih kadang lupa saya ucapkan dalam pergaulan dengan prosentase $3,47 \%$ Saya merasa sulit bergaul/kaku dengan teman-teman di sekolah dengan prosentase $2,97 \%$, Saya merasa sulit bergaul/kaku dengan teman-teman di sekolah dengan prosentase 2,97\%. Selain itu, berdasarkan wawancara terhadap guru BK pada tanggal 9 Mei 2018 bahwa ternyata sebagian besar siswa sering berbicara kurang sopan dan santun terhadap teman sebaya, guru dan staff $\mathrm{TU}$, sulit mengungkapkan pendapatnya di depan kelas, sering berbeda pendapat dengan orang lain dan kurang 
Jurnal Bimbingan dan Konseling

menghargai guru yang sedang mengajar dikelas. Menurut Erikson (dalam Cintia Kusuma Dewi 2015:2) seorang remaja bukan sekedar mempertanyakan siapa dirinya tapi bagaimana ia menjadi bermakna dan dimaknakan. Keinginan mereka untuk diakui dan diterima dalam kelompok akan menjadi fokus remaja dalam berinteraksi di lingkungan sosial yang menyebabkan timbulnya konformitas teman sebaya. Untuk meningkatkan konformitas positif siswa dipelukan pengarahan dan bimbingan dari orang tua dan sekolah, peran orang tua di rumah sangat diperlukan untuk mengarahkan dan membimbing agar bisa besikap dengan sopan dan beretika ketika berada di dalam rumah, Kesibukan orang tua membuat pengawasan terhadap siswa menjadi lemah sehingga bimbingan dan arahan terhadap siswa menjadi lemah yang menyebabkan siswa bersikap kurang baik dan kurang sopan dengan orang lain tanpa tahu mana sikap yang baik dan mana yang dapat berdampak buruk untuk dirinya. Selain orang tua, peran lembaga pendidikan atau sekolah sangatlah penting dalam mengembangkan konformitas positif siswa. Pihak sekolah dalam mengembangkan konformitas positif siswa melalui layanan bimbingan dan konseling di sekolah. Mengatasi hal tersebut, setiap satuan pendidikan harus memberikan layanan yang dapat memfasilitasi siswa secara optimal berupa bimbingan dan konseling. Salah satu bentuk layanan yang bisa digunakan untuk membantu tugas perkembangan siswa adalah dengan memberikan layanan bimbingan kelompok dengan media audio visual.

\section{Konformitas}

Untuk menjadi bagian dari sebuah kelompok seseorang dengan mudah memiliki sikap dan bertingkah laku sesuai dengan norma kelompok yang disebut konformitas. Baron \& Bryne (2003:53) konformitas adalah suatu jenis pengaruh sosial dimana individu mengubah sikap dan tingkah laku mereka agar sesuai dengan norma yang ada. Penyesuaian terhadap kelompok sosial karena adanya tuntutan dari kelompok tersebut untuk menyesuaikan meskipun tuntutan tersebut tidak terbuka agar sesuai dengan norma sosial yang ada. Sikap konformis pada diri individu muncul karena adanya suatu norma sosial yang menuntut seseorang untuk menyesuaikan norma-norma yang ada. Menurut Sear, Freedman, \& Peplau (dalam Anas, 2007:I19) Seringkali individu, kelompok atau organisasi berusaha agar pihak lain menampilkan suatu perilaku tertentu pada saat pihak lain tersebut tidak ingin menampilkannya. Bila seseorang menampilkan perilaku tertentu karena setiap orang atau orang-orang lain menampilkan perilaku tersebut, maka perilaku tersebut dinamakan konformitas. Menampilkan suatu tindakan karena orang lain juga disebut konformitas. Orang benar-benar menyesuaikan diri meskipun dengan melakukan itu dia menentang persepsinya sendiri. Mereka tidak selalu mau menerima apa yang dikatakan orang lain, sering kali mereka tetap yakin bahwa penilaian mereka benar. Namun, bila diminta untuk memberikan jawaban secara terbuka, mereka memberikan jawaban keliru yang sama dengan jawaban yang diberikan orang lain (Sears, 1985: 103).

Berdasarkan pemaparan tersebut dapat disimpulkan bahwa konformitas adalah penyesuaian atau perubahan tingkah laku individu dalam sebuah kelompokkarena adanya tuntutan ataupun tekanan sebagai tuntutan kelompok yang bertujuan agar individu tersebut dapat diterima dalam kelompok tersebut. Menurut Sears dkk (1985:85) aspek-aspek konformitas yaitu:

a. Aspek kekompakan, yang dimaksud dengan istilah kekompakan adalah jumlah total kekuatan yang menyebabkan orang tertarik pada suatu kelompok dan yang membuat mereka ingin tetap menjadi anggotanya. 
Jurnal Bimbingan dan Konseling

Kekompakan mengacu pada kekuatan yang menyebabkan para anggotanya menetap dalam suatu kelompok.

b. Aspek kesepakatan, aspek yang sangat penting bagi timbulnya konformitas adalah kesepakatan pendapat kelompok. Individu yang dihadapkan pada keputusan kelompok yang bulat akan mendapat tekanan yang kuat untuk menyesuaikan pendapatnya. Namun, bila kelompok tidak bersatu akan tampak adanya penurunan konformitas.

c. Aspek ketaatan, konformitas merupakan bagian dari persoalan mengenai bagaimana membuat individu rela melakukan sesuatu yang sebenarnya tidak ingin mereka lakukan. Salah satu caranya adalah melalui tekanan sosial.

Penelitian yang dilakukan oleh Asch (Baron \& Byrne, 2005: 56), menunjukkan terdapat empat faktor yang menentukan seseorang menuruti tekanan konformitas, yaitu:

a.

Kohesivitas (Cohesiveness),
didefinisikan sebagai $\begin{array}{r}\text { derajat } \\ \text { ketertarikan yang dirasa oleh individu }\end{array}$
terhadap suatu kelompok. Ketika
kohesivitas tinggi maka tekanan untuk
melakukan konformitas bertambah
besar. Sebaliknya apabila kohevitas
rendah maka teknanan untuk
konformitas juga rendah. Apabila
seseorang memiliki ketertarikan yang
tinggi terhadap suatu kelompok maka
salah satu cara untuk diterima oleh
orang-orang tersebut atau sebuah
kelompok adalah dengan menjadi
seperti mereka dalam berbagai hal, dan
sebaliknya apabila seseorang tidak
tertarik dengan sebuah kelompok
tersebut makan perilaku konformitas
tidak terjadi.

b. Ukuran Kelompok, faktor yang memiliki pengaruh besar penting dalam kecenderungan melakukan konformitas adalah ukuran kelompok. Semakin besar ukuran kelompok tersebut, maka semakin besar pula kecenderungan seorang untuk ikut serta dalam kelompok tersebut.

c. Norma Sosial Deskriptif, norma sosial deskriptif atau himbauan (descriptive norms) adalah norma yang hanya mendeskripsikan apa yang sebagian orang lakukan pada situasi tertentu. Norma ini mempengaruhi tingkah laku dengan cara memberitahu mengenai apa yang umumnya dianggap efektif atau adaptif pada situasi tertentu.

d. Norma sosial injungtif atau perintah (injunctive norms) adalah norma yang menetapkan apa yang harus dilakukan dan tingkah laku apa yang diterima atau tidak diterima pada situasi tertentu. Individu dengan mudah melakukan konformitas apabila ada sebuah perintah yang mengharuskan individu berperilaku sama sesuai dengan norma.

\section{Bimbingan Klasikal dengan Media Audio Visual}

Menurut Winkel dan Hastuti (2006:56I) bimbingan klasikal adalah bimbingan yang diberikan kepada sejumlah siswa yang tergabung dalam suatu satuan kegiatan pengajaran. Menurut Siwabessy dan Hastuti (2008:136) mengatakan bimbingan klasikal adalah bimbingan yang berorientasi pada kelompok siswa dalam jumlah cukup besar antara 30-40 orang siswa sekelas. Sedangan menurut Yusuf dan Nurihsan (2008:26) bimbingan klasikal sering disebut sebagai layanan dasar yakni layanan bantuan bagi peserta didik (siswa) melalui kegiatankegiatan secara klasikal yang disajikan secara sistematis dalam rangka membantu siswa mengembangkan potensinya secara optimal. Dari berbagai pengertian di atas, maka 
pengertian bimbingan klasikal adalah suatu kegiatan pengajaran bagi siswa dalam jumlah yang cukup besar yang disajikan secara sistematis. Audio visual adalah perangkat sound system yang dilengkapi dengan penampilan gambar, biasanya digunakan untuk presentasi, home theater dan sebagainya ( Munir, 20I3:267).

Menurut Kustandi (2011:30) audio visual merupakan cara menghasilkan atau menyampaikan materi dengan menggunakan mesin-mesin mekanis dan elektronik untuk menyajikan pesan-pesan audio dan visual. Berdasarkan penjelasan di atas dapat disimpulkan bahwa bimbingan kalsikal dengan media audio visual merupakan suatu kegiatan pengajaran bagi siswa dalam jumlah yang cukup besar yang disajikan secara sistematis yang diberikan kepada siswa menggunakan media untuk membantu pemenuhan kebutuhannya dalam menyelesaikan permasalahan menggunakan pendengaran dan penglihatan dalam proses kegiatan dengan seperangkat alat untuk menyampaikan materi dengan menggunakan alat yang dapat memproyeksikan gambar bergerak dan bersuara seperti film dan video.

\section{METODE PENELITIAN}

Dalam penelitian ini, peneliti menggunakan metode kuantitatif dengan jenis penelitian true eksperimen dengan model pretest-posttest control group design. Dalam desain ini terdapat dua kelompok yang dipilih secara random, kemudian diberi pre-test dan post test untuk mengetahui keadaan awal dan keadaan akhir adakah perbedaan hasil antara kelompok eksperimen dan kelompok kontrol (Sugiyono, 2016: 76). Menurut Sugiyono (2013: II8) sampling adalah teknik pengambilan sampel. Peneliti dalam melakukan pengambilan sampel menggunakan teknik culster random sampling, yaitu pengambilan sampel berdasarkan daerah populasi yang ditetapkan. Dalam cluster random sampling, populasi diambil secara acak dengan cara membuat undian dengan kertas dari seluruh kelas yang ada lalu diambil dan sampling yang akan dijadikan penelitian. Dan dari hasil undian peneliti menemukan kelas VIII D sebagai kelas eksperimen dan kelas A sebagai kelas kontrol yang akan dijadikan penelitian, dari lima kelas yaitu kelas VIII A, VIII B, VIII C, VIII D, VIII E. Dalam penelitian ini proses eksperimen pengumpulan data dapat dibagi menjadi tiga tahap yaitu pesiapan, pelaksanaan, dan akhir. Dimana setiap tahap tersebut peneliti memuat beberapa langkah-langkah sebagai berikut :

\section{Persiapan Eksperimen}

a. Peneliti melaksanakan tryout skala komunikasi interpersonalyang berjumlah 32 siswa untuk menguji validitas dan reliabilitas.

b. Dalam penelitian ini peneliti menggunakan teknik Cluster Random, dengan cara acak mengambil kelas acak untuk kelompok eksperiemen.

c. Peneliti melaksanakan pre-test dengan menyebar skala komunikasi interpersonal yang berjumlah 32 siswa.

\section{Pelaksanaan}

a. Sesudah ditetapkan kelompok tersebut, maka kelompok kontrol tidak diberikan layanan bimbingan kelompok. Sedangkan kelompok eksperimen diberikan tindakan layanan bimbingan kelompok dengan media audio visual oleh peneliti.

b. Dilaksanakan treatmen terhadap kelompok eksperimen sebanyak 6 kali kurang lebih selama dua bulan, sedangkan kelompok kontrol tidak diberikan layanan.

\section{Akhir Eksperimen}

a. Sesudah mendapatkan perlakuan, maka pada kelompok eksperimen dan kelompok kontrol diberikan test bersamaan (post-test). 
Jurnal Bimbingan dan Konseling

b. Peneliti melakukan analisis menggunakan uji-t untuk mengetahui pengaruh layanan bimbingan klasikal dengan media audio visual.

HASIL

\section{PENELITIAN}

PEMBAHASAN

Data deskripsi pretes dan posttest kelompok eksperimen dengan rentang interval, sebagai berikut :

Rentang kelas interval = Jumlah Skor Maksimum - Jumlah Skor Minimum 4 Kategori

$$
\text { Rentang }=\frac{84-21}{4}=\frac{63}{4}=15,75=16
$$

Berikut adalah distribusi bergolong yang dapat dilihat pada tabel di bawah ini.

\section{Tabel I}

\section{Kategori Distribusi Bergolong}

\begin{tabular}{|l|l|l|}
\hline No & Kriteria & Interval \\
\hline 1 & Sangat tinggi & $70-84$ \\
\hline 2 & Tinggi & $54-69$ \\
\hline 3 & Rendah & $38-53$ \\
\hline 4 & Sangat rendah & $21-37$ \\
\hline
\end{tabular}

Berikut perbandingan hasil pretest dan posttest kelompok eksperimen siswa kelas VIII SMP Negeri 5 Rembang, sebagai berikut :

Tabel 2

\section{Perbandingan Hasil Pretest dan Posttest}

\begin{tabular}{|c|c|c|c|c|}
\hline \multicolumn{3}{|c|}{ Pre-test } & \multicolumn{2}{c|}{ Post-test } \\
\hline No & Skor & Kategori & Skor & $\begin{array}{c}\text { Kat } \\
\text { ego } \\
\text { ri }\end{array}$ \\
\hline I & 69 & T & 7 I & R \\
\hline 2 & 70 & ST & 7 I & T \\
\hline 3 & 58 & T & 6 I & T \\
\hline 4 & 66 & T & 66 & T \\
\hline 5 & 67 & T & 69 & T \\
\hline 6 & 57 & T & 60 & T \\
\hline
\end{tabular}

\begin{tabular}{|c|c|c|c|c|}
\hline 7 & 62 & $\mathrm{~T}$ & $6 \mathrm{I}$ & $\mathrm{T}$ \\
\hline 8 & $6 \mathrm{I}$ & $\mathrm{T}$ & $6 \mathrm{I}$ & $\mathrm{R}$ \\
\hline 9 & 68 & $\mathrm{~T}$ & 68 & $\mathrm{R}$ \\
\hline $\mathrm{I} 0$ & 67 & $\mathrm{~T}$ & 65 & $\mathrm{R}$ \\
\hline $\mathrm{II}$ & 67 & $\mathrm{~T}$ & 67 & $\mathrm{~T}$ \\
\hline $\mathrm{I} 2$ & 67 & $\mathrm{~T}$ & 67 & $\mathrm{R}$ \\
\hline $\mathrm{I} 3$ & 54 & $\mathrm{~T}$ & 55 & $\mathrm{R}$ \\
\hline $\mathrm{I} 4$ & 64 & $\mathrm{~T}$ & 63 & $\mathrm{~T}$ \\
\hline $\mathrm{I} 5$ & 67 & $\mathrm{~T}$ & 66 & $\mathrm{~T}$ \\
\hline $\mathrm{I} 6$ & 65 & $\mathrm{~T}$ & 67 & $\mathrm{~T}$ \\
\hline $\mathrm{I} 7$ & 54 & $\mathrm{~T}$ & 58 & $\mathrm{~T}$ \\
\hline $\mathrm{I} 8$ & 64 & $\mathrm{~T}$ & 70 & $\mathrm{~T}$ \\
\hline $\mathrm{I} 9$ & 64 & $\mathrm{~T}$ & 64 & $\mathrm{R}$ \\
\hline 20 & 54 & $\mathrm{~T}$ & 54 & $\mathrm{~T}$ \\
\hline $2 \mathrm{I}$ & 63 & $\mathrm{~T}$ & 67 & $\mathrm{~T}$ \\
\hline 22 & 53 & $\mathrm{R}$ & 49 & $\mathrm{~T}$ \\
\hline 23 & 63 & $\mathrm{~T}$ & 70 & $\mathrm{~T}$ \\
\hline 24 & 63 & $\mathrm{~T}$ & 70 & $\mathrm{~T}$ \\
\hline 25 & 63 & $\mathrm{~T}$ & 63 & $\mathrm{R}$ \\
\hline 26 & 63 & $\mathrm{~T}$ & 63 & $\mathrm{~T}$ \\
\hline 27 & 63 & $\mathrm{~T}$ & 63 & $\mathrm{~T}$ \\
\hline 28 & 66 & $\mathrm{~T}$ & 66 & $\mathrm{~T}$ \\
\hline 29 & 50 & $\mathrm{R}$ & 53 & $\mathrm{~T}$ \\
\hline 30 & 58 & $\mathrm{~T}$ & 59 & $\mathrm{~T}$ \\
\hline $3 \mathrm{I}$ & 54 & $\mathrm{~T}$ & 57 & $\mathrm{R}$ \\
\hline 32 & 64 & $\mathrm{~T}$ & 67 & $\mathrm{~T}$ \\
\hline $\mathrm{Jml}$ & $\mathrm{I} 988$ & & $203 \mathrm{I}$ & \\
\hline $\bar{x}$ & 198,8 & & $203, \mathrm{I}$ & \\
\hline & & & & \\
\hline
\end{tabular}

\section{Gambar I}

\section{Grafik Rata-Rata Hasil Pretest dan} Posttest

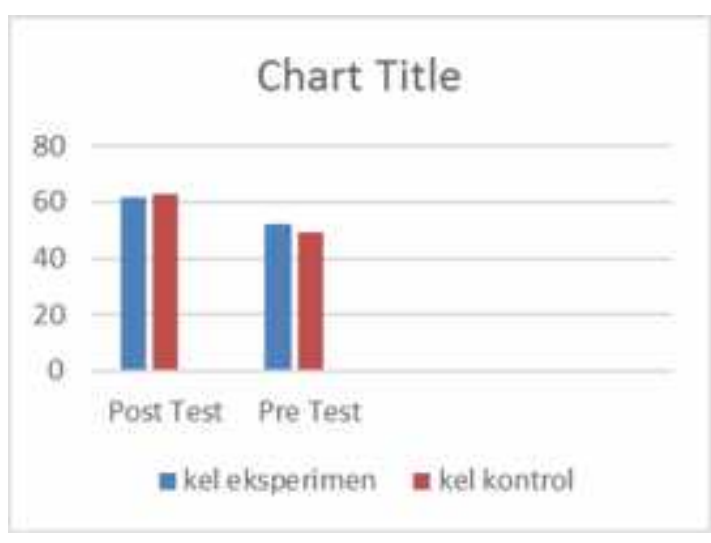


Jurnal Bimbingan dan Konseling

Uji Hipotesis $\boldsymbol{t}$ Test

\begin{tabular}{|c|c|c|c|c|}
\hline No & $\mathbf{X}_{1}$ & $X_{2}$ & $x$ & $x$ \\
\hline I & 71 & 56 & 5041 & 3136 \\
\hline 2 & 71 & 61 & $504 I$ & 3721 \\
\hline 3 & 61 & 57 & 3721 & 3249 \\
\hline 4 & 66 & 54 & 4356 & 2916 \\
\hline 5 & 69 & 51 & 4761 & 2601 \\
\hline 6 & 60 & 50 & 3600 & 2500 \\
\hline 7 & 61 & 42 & 3721 & 1764 \\
\hline 8 & 61 & 49 & 3721 & 2401 \\
\hline 9 & 68 & 46 & 4624 & 2116 \\
\hline 10 & 65 & 51 & 4225 & 2601 \\
\hline II & 67 & 53 & 4489 & 2809 \\
\hline 12 & 67 & 59 & 4489 & 3481 \\
\hline 13 & 55 & 46 & 3025 & 2116 \\
\hline 14 & 63 & 52 & 3969 & 2704 \\
\hline 15 & 66 & 54 & 4356 & 2916 \\
\hline 16 & 67 & 57 & 4489 & 3249 \\
\hline 17 & 58 & 52 & 3364 & 2704 \\
\hline 18 & 70 & 53 & 4900 & 2809 \\
\hline 19 & 64 & 56 & 4096 & 3136 \\
\hline 20 & 54 & 47 & 2916 & 2209 \\
\hline 21 & 67 & 56 & 4489 & 3136 \\
\hline 22 & 49 & 48 & 2401 & 2304 \\
\hline 23 & 70 & 59 & 4900 & 3481 \\
\hline 24 & 70 & 56 & 4900 & 3136 \\
\hline 25 & 63 & 55 & 3969 & 3025 \\
\hline 26 & 63 & 56 & 3969 & 3136 \\
\hline 27 & 63 & 58 & 3969 & 3364 \\
\hline 28 & 66 & 58 & 4356 & 3364 \\
\hline 29 & 53 & 50 & 2809 & 2500 \\
\hline 30 & 59 & 54 & $348 I$ & 2916 \\
\hline 31 & 57 & 56 & 3249 & 3136 \\
\hline 32 & 67 & 58 & 4489 & 3364 \\
\hline JML & 2031 & 1710 & 129885 & 92000 \\
\hline
\end{tabular}

Perhitungan untuk uji hipotesis sebagai berikut:

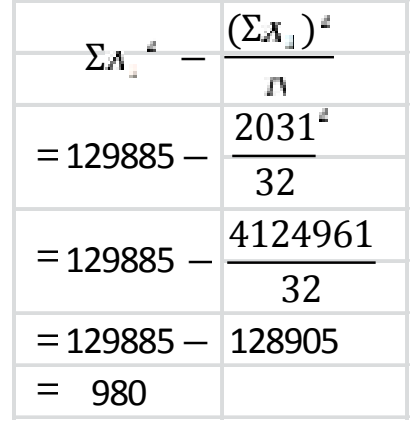

$$
\begin{aligned}
& \Sigma_{\Lambda_{4}}{ }^{2}-\frac{\left(\Sigma_{\Lambda_{1}}\right)^{a}}{n} \\
& =92000-\frac{1710^{2}}{32} \\
& =78038-\frac{2924100}{32} \\
& =92000-93571 \\
& =-1571 \\
& \begin{array}{l}
X_{1}=\frac{\Sigma \delta 1}{n}=\frac{2031}{32}=63,47 \\
X_{4}=\frac{\Sigma \delta 2}{n}=\frac{1710}{32}=53,44
\end{array} \\
& \mathrm{t}=\frac{\overline{x_{1}-\bar{x}_{2}}}{\sqrt{\frac{\sum x_{1} a+\sum x_{2} 2}{N_{1}\left(N_{2-1}\right)}}} \\
& =\frac{10,03}{\sqrt{\frac{2031+171}{32(32-1)}}} \\
& =\frac{10,03}{\sqrt{\frac{3741}{992}}} \\
& \begin{array}{l}
=10,03 \\
\hline=5,17 \\
\hline=54
\end{array}
\end{aligned}
$$

Dengan $\mathrm{dbN}(32)-2=30$ dengan taraf signifikan $5 \%$ untuk ttabel $(30=2,042)=5,17$ maka thitung > ttabel $5,17>2,042$. Berdasarkan perhitungan uji- $t$ diperoleh hasil $t_{\text {hitung }}$ sebesar 15,17 sementara $t_{\text {tabel }}$ dengan $\mathrm{db}$ $=(32)-2=30$ dan taraf signifikansi $5 \%$ sebesar 2,042. Karena jumlah thitung lebih besar dari tabelmaka $\left(\mathrm{H}_{\circ}\right)$ ditolak dan $\left(\mathrm{H}_{\mathrm{a}}\right)$ diterima. Dapat disimpulkan bahwa ada 
perbedaan konformitas positif siswa antara kelompok eksperimen dan kelompok kontrol.

Berdasarkan hasil pengujian hipotesis menggunakan uji-t, dapat diketahui bahwa hasil $t_{\text {hitung }}(15,17)>t_{\text {tabel }}(2,042)$ pada taraf signifikan $5 \%$ yang berarti $t_{\text {hitung }}>t_{\text {rabeil }}$ Dengan demikian dapat disimpulkan bahwa layanan bimbingan klasikal dengan media audio visual dapat mempengaruhi konformitas positif siswa kelas VIII SMP Negeri 5 Rembang. Sehingga hipotesis yang berbunyi "Pengaruh bimbingan klasikal dengan media audio visual untuk mengembangkan konformitas positif Siswa Kelas VIII SMP Negeri 5 Rembang" dapat diterima. Berdasarkan hasil analisis data yang dilakukan dari hasil skor terendah kelompok eksperimen yaitu 50 dan skor terendah kelompok kontrol yaitu 42 sedangkan skor tertinggi kelompok eksperimen yaitu 70 dan skor tertinggi kelompok kontrol yaitu 57. Rata-rata hasil pre-test diperoleh 62,I untuk kelompok eksperimen dan 5I,I untuk kelompok kontrol. Sedangkan pada hasil posttest kelompok eksperimen diperoleh Setelah diberikan treatment bimbingan klasikal dengan media audio visual pada kelompok eksperimen terjadi peningkatan skor dibandingkan dengan kelompok kontrol yang tidak diberikan bimbingan klasikal media audio visual. Rata-rata skor kelompok eksperimen adalah $62,1 \%$ pada kategori tinggi. Rata-rata hasil posttest konformitas positif siswa menunjukan peningkatan dibandingkan dengan rata-rata hasil pretest pada skala konformitas positif. Dari data tersebut dapat dilihat bahwa ada peningkatan konformitas positif sebesar I,4 poin setelah mendapatkan treatment.

Berdasarkan hasil evaluasi proses yang peneliti lakukan selama pemberian treatmen, terlihat siswa sangat antusias dan aktif dalam mengikuti bimbingan klasikal dengan media audio visual. Hal tersebut didukung pula dengan evaluasi hasil yang peneliti lakukan setelah pemberian treatmen dengan melakukan observasi terhadap siswa yang masuk dalam kelompok eksperimen.Terlihat ada perbedaan sikap lebih menghormati dan mau menerima teman lainnya, mampu membaur dengan lainnya. Dengan demikian pemberian bimbingan klasikal dengan media audio visual yang dilakukan merupakan tepat sasaran dan tepat materi.Hal ini karena siswa telah mendapatkan bimbingan klasikal mampu mengembangkankonformitas positif. Pengaruh bimbingan klasikal dengan media audio visual untuk mengembangkan konformitas siswa kelas VIII SMP Negeri 5 Rembang efektif digunakan.Dilihat dari awal sebelum diberikan treatmen masih banyak siswa yang acuh dengan lingkungan sekitar, mereka terlalu mementingkan dirinya sendiri dan kurang memiliki empati terhadap sesama. Setelah diberikan treatmen terdapat kemajuan yang lebih baik yaitu siswa sudah mampu memperhatikan orang lain yang ada di sekitarnya, munculnya sikap empati dari mereka. Siswa dapat menerapkan sikap sopan dan santun kepada sesama dan lebih menghargai pendapat orang lain. Faktor yang mempengaruhi adanya konformitas positif itu karena adanya sikap empati secara tepat terhadap orang lain dan menghargai dengan yang lainnya.

\section{SIMPULAN DAN SARAN}

Bimbingan klasikal dengan media audio visualberpengaruh terhadap konformitas positif siswa kelas VIII SMP Negeri 5 Rembang. Simpulan ini didasarkan pada perbedaan hasil pretest dan posttest skala komunikasi Interpersonal. Terjadi peningkatan skor rata-rata sebelum dan sesudah diberikan bimbingan klasikal dengan media audio visual.

Pada kelompok eksperimen terjadi peningkatan dari 6I,I menjadi 62,5 dengan demikian terjadi peningkatan yang cukup besar yaitu I,4 point. Sehingga dapat disimpulkan bahwa bimbingan klasikal siswa kelas VIII SMP Negeri 5 Rembang., menjadi lebih baik setelah diberikan bimbingan klasikal dengan media audio visual Hipotesis $(\mathrm{Ha})$ awal yang berbunyi "Ada Pengaruh bimbingan klasikal dengan media audio visual untuk mengembangkan konforitas positif siswa kelas VIII SMP Negeri 5 Rembang". 


\section{Jurnal Bimbingan dan Konseling}

\section{DAFTAR PUSTAKA}

Anas, Muhammad. 2007. Pengantar Psikologi Sosial. Makassar: Universitas Negeri Makassar.

Asch (Baron, Robert \& Bryne, Donn). 2005. Psikologi Sosial. Jakarta: Erlangga.

Baron, Robert \& Bryne, Donn. 2003. Psikologi Sosial. Jakarta: Erlangga.

Baron, Robert \& Bryne, Donn. 2005. Psikologi Sosial. Jakarta: Erlangga.

Kustandi, Cecep \& Sutjipto. 2016. Media Pembelajaran Manual dan Digital. Bogor.Ghalia Indonesia.

Kusuma, Dewi Cintia. 2015. "Pengaruh Konformitas Teman Sebaya Terhadap Perilaku Bullying Pada Siswa SMA Negeri I Depok Yogyakarta". Artikel E-Journal. UNY.

Munir. 2013. Multimedia Konsep \& Aplikasi dalam Pendidikan. Bandung: Alfabeta.

Nurihsan. 2008. Bimbingan dan Konseling dalam Berbagai Latar Kehidupan. Bandung: Refika aditama.

Permadi, Ade Salahudin \& Muchlis Saini. 2017. Upaya Meningkatkan Hasil Belajar IPA melalui Penerapan Media Pembelajaran Berbasis Multimedia Peserta Didik. Bitnet: Jurnal Pendidikan Teknologi Informasi, 2(2):20-26.

Putra, Chandra Anugrah. 2016. Pengaruh Strategi Pembelajaran Berbasis Proyek Perancangan dan Kecerdasan LogikMatematik Terhadap Kompetensi Merancang Web. Jurnal Teknologi Pendidikan, I8(2):90-I0I.

Sears, 1985. Psikologi Sosial. Jakarta: PT Gelora Aksara Pratama.

Setyawan, Dedy \& Muhammad Fitriadi. Penggunaan Media Tiga Dimensi dalam Meningkatkan Hasil Belajar Matematika Peserta Didik. Bitnet: Jurnal Pendidikan Teknologi Informasi, 2(I): I-7.

Siwabessy, Louse B dan Sri Hastoeti. 2008. Bahan Ajar Sertifikasi Guru Bimbingan dan
Konseling dalam Jabatan Melalui Jalur Pendidikan. Jakarta: Depdiknas.

Sugiyono. 2013. Metode Penelitian Kuantitatif, Kualitatif dan $R n D$ \& $D$. Bandung. Tarsito.

Sugiyono. 2016. Metode Penelitian Kuantitatif, Kualitatif dan $R n D$ \& D. Bandung. Tarsito.

Winkel. 2006. Bimbingan dan Konseling di Institusi Pendidikan.Yogyakarta: Media Abadi. 